
\title{
$\begin{array}{ll}\text { Research Square } & \text { They should not be considered conclusive, used to inform clinical practice, } \\ \text { or referenced by the media as validated information. }\end{array}$
}

\section{Health care providers' perspectives on providing end-of-life psychiatric care between cardiovascular and oncological hospitals: a cross-sectional questionnaire survey}

\author{
ICHIKURA Kanako ( $\nabla$ ichikura@kitasato-u.ac.jp) \\ Kitasato University Schoool of Allied Health Sciences \\ MATSUOKA Shiho \\ Tokyo Medical and Dental University \\ CHIBA Hiroki \\ Kitasato University School of Medicine \\ ISHIDA Hina \\ Kitasato University Graduate School of Medical Sciences \\ FUKASE Yuko \\ Kitasato University Schoool of Allied Health Sciences \\ MURASE Hanako \\ Kitasato University Schoool of Allied Health Sciences \\ TAGAYA Hirokuni \\ Kitasato University Schoool of Allied Health Sciences \\ TAKEUCHI Takashi \\ Tokyo Medical and Dental University \\ MATSUSHIMA Eisuke \\ Tokyo Medical and Dental University
}

\section{Research Article}

Keywords: End-of-life, terminal, palliative care, psychiatric care, psychological care, distress

Posted Date: February 22nd, 2022

DOI: https://doi.org/10.21203/rs.3.rs-1054248/v2

License: (9) (7) This work is licensed under a Creative Commons Attribution 4.0 International License. Read Full License 


\section{Abstract}

Background: Psychological distress is a serious problem for patients with heart disease or cancer at the end of life. The aim of this study was to compare the barriers to providing end-of-life psychiatric care in cardiovascular compared to oncological settings.

Methods: In this cross-sectional questionnaire survey conducted in Japan, we mailed questionnaires to physicians and nurses in 347 oncological and 427 cardiovascular hospitals in March 2018 to assess health care providers' perspectives. First, we applied the Palliative Care Difficulties Scale and assessed endof-life psychiatric care difficulties. Second, we asked about barriers to providing end-of-life psychiatric care in free description.

Results: A total of 224 oncological and 213 cardiovascular hospitals responded to the questionnaires. The mean scores of palliative and end-of-life psychiatric care difficulties showed no significant differences between oncological and cardiovascular hospitals. Eight barriers to providing end-of-life psychiatric care were identified and were based on patients' personal, interfamilial, clinicians' personal, clinician-patient communication, end-of-life care, psychiatric care, systematic or environmental, and disease-specific problems. In addition, health care providers in cardiovascular hospitals were found to have a significantly higher rate of disease-specific issues compared with oncological hospitals.

Conclusions: Both oncological and cardiovascular physicians and nurses have similar difficulties in providing end-of-life psychiatric care. However, health care providers of cardiovascular hospitals particularly experience heart disease-specific problems, such as unpredictability of prognosis or insufficiency of guideline development.

\section{Background}

Heart failure (HF) is a fatal, severe medical illness that can impose a serious burden on patients and their caregivers. The World Health Organization estimated the worldwide mortality from cardiovascular disease at 15.2 million in 2016 [1], making it the most common cause of death (40\%) among middle-aged and older adults [2]. Despite the recent rapid progress in medical treatments, the median survival rate after patients' first hospitalization is low in severe HF (2.1 years) [3]. In addition, HF has inflicted a burden of $\$ 180$ million on the global health system [4].

Patients with advanced HF commonly experience psychological symptoms, the most common of which are depression and anxiety, as well as physical symptoms, such as dyspnea, pain, or fatigue [5,6]. Severe clinical depression is diagnosed in 12 to $33 \%$ of all patients with heart disease [7, 8], and in 38 to $42 \%$ of those with severe HF featuring New York Heart Association class III-IV symptoms [9]. Among HF patients, $29 \%$ exhibit severe clinically significant anxiety symptoms, and $9 \%$ have anxiety disorders, including general anxiety disorders $[6,10]$. In addition, psychological symptoms have a highly negative impact on the quality of life and are associated with poor treatment adherence, severe physical symptoms, long-term hospitalization, and a reduced survival rate [11]. Therefore, psychological symptoms, such as depression or anxiety, are particularly challenging problems for patients with end-stage HF [12, 13].

Psychiatric interventions are necessary for patients with depressive HF. However, there is inadequate evidence for the efficacy of pharmacological treatments, such as antidepressants, in patients with HF [14, 15], and psychiatric medication increases the risk of death among HF patients [16]. Nevertheless, psychological treatment has received attention among patients with HF in recent years, and cognitive behavioral therapy in particular has been shown to improve psychological symptoms $[17,18]$. Relaxation, meditation, and mindfulness-based psychoeducation can also alleviate psychological distress $[19,20]$. However, there is limited evidence and guidance on the efficacy of such psychiatric care among patients with terminal HF [21, 22].

In patients with end-stage cancer, psychiatric or psychological treatment can improve psychological distress [23-25]. Workshops or guidelines for oncologists can also enhance their practical skills in end-of-life psychiatric care [26, 27]. A comparison between patients with end-stage HF and those with end-stage cancer could provide useful insights into potential barriers to applying psychiatric care for affected individuals. In addition, no study has examined the barriers in psychiatric management instead of pain management in end-of-life patients using a qualitative bottom-up approach [28]. Moral distress in health care providers decreases their motivation, capacity, and communication, which in turn can have a negative impact on patients' psychological distress [29, 30].

The aims of this study were to identify the barriers to providing psychiatric care for end-of-life patients among health care providers, and to compare such barriers between cardiovascular and oncological hospitals.

\section{Methods}

\section{Design and participants}

This was a national cross-sectional survey conducted among Japanese health care providers in oncological and cardiovascular hospitals using selfcompleted questionnaires. We mailed the questionnaires to the chief physicians of respiratory and cardiovascular internal medicine of 347 designated cancer hospitals and 427 ICD specialized hospitals, asking them to deliver the questionnaires directly to oncological and cardiovascular physicians and nurses in March 2018. Designated cancer hospitals, recommended by the prefectural governments, can provide high-quality cancer treatment guaranteed by the Ministry of Health, Labour and Welfare in Japan. They provide specialized cancer treatments, establish local cooperation systems for cancer treatments, and provide consultation, support, and information for cancer patients. Additionally, ICD specialized hospitals can operate implantation of implantable cardioverter-defibrillators (ICDs).

\section{Ethics}


Our study was approved without undergoing assessment by the institutional review board at the Tokyo Medical and Dental University in Japan, as it was an anonymized non-invasive self-completed questionnaire study for health care providers. However, all procedures were in accordance with the ethical standards of the responsible committees on human experimentation (institutional and national) and with the Helsinki Declaration of 1975, as revised in 2000. All participating physicians and nurses were volunteers and were not provided with any incentive to participate. The anonymized questionnaires were individually returned from each health care provider and not specified by an individual person or facility.

\section{Demographic and clinical characteristics}

We collected demographic and clinical information from the self-completed questionnaires. First, we included the following data: sex, age, and medical license of the staff of each health care provider. Second, we included the following data: area (Hokkaido/Tohoku, Kanto/Koshinetsu, Chubu/Hokuriku, Kinki, Chugoku/Shikoku, and Kyushu/Okinawa area), hospital type (national medical center, academic medical center, general hospital except academic medical center, specialized hospital), the number of hospital beds, and the presence of a palliative care unit, palliative care team, liaison psychiatry team, palliative care physicians, psychiatrists, and psychologists at hospitals.

\section{Outcome measures}

\section{Difficulty of providing palliative care}

The Palliative Care Difficulties Scale, a 15-item self-reported scale, was developed in Japan [31]. It is a 4-point Likert-type scale ranging from 0 to 3 (overall score range: 0-42). The scale contains five factors with three items each: (1) alleviating symptoms, (2) expert support, (3) multidisciplinary communication, (4) communication with patient/family, and (5) community coordination. The reliability and validity of this measure were sufficiently supported in an earlier study [31].

\section{Difficulty of providing end-of-life psychiatric care}

We developed the following question for assessing the difficulty of providing end-of-life psychiatric care: "Do you feel challenged to provide psychiatric care for patients at their end of life?"; possible answers were "yes" or "no."

\section{Barriers to providing end-of-life psychiatric care}

To identify barriers to providing end-of-life psychological care, we asked participants who answered "yes" in the above question: "Why do you feel challenged to provide psychological care for patients at their end of life?" and asked to submit written answers in free description.

\section{Qualitative analyses}

Content analysis was used to analyze free description data. Content analysis is an objective and systematic procedure used to draw conclusions by creating categories of data from verbatim or unstructured data [32]. We conducted a quantitative content analysis according to previous studies in palliative care settings [33,34]. Our content analysis procedure was conducted as follows: (1) all text data were divided into thematic units, which are the units of words with one logical meaning; (2) two researchers, a clinical psychologist and a cardiovascular nurse (IK and MS, respectively) extracted all statements from the free descriptions related to the study topic, such as the barriers to providing end-of-life psychiatric care; (3) a clinical psychologist (IK), a cardiovascular nurse (MS), and two psychiatrists in the palliative care team (ME and TT) carefully conceptualized similarities and differences in the content, and defined all categories; and (4) two coders, a student of psychology and a psychiatric clinical nurse, independently determined how each thematic unit that was identified corresponded with any category. The concordance rate and kappa coefficient of the determinations of the categories were used as reliability indicators. The kappa coefficient was calculated using $20 \%$ of the data and random sampling was conducted based on the data from a standard set derived from a previous study, with more than $10 \%$ or 50 units of data $[35,36]$.

\section{Statistical analyses}

First, we summarized the characteristics of the participants and hospitals using standard descriptive statistics. Second, the mean difference in difficulties in providing palliative care was compared between oncological and cardiovascular hospitals using a $t$ test, and the frequency of difficulties in providing end-oflife psychiatric care was compared between oncological and cardiovascular hospitals using a $\chi^{2}$ test. Third, the frequency of the thematic units that were categorized in the above content analysis was compared between health care providers in oncological and cardiovascular hospitals using a $\chi^{2}$ test. The significance level was set at 5\%. All data were analyzed using IBM SPSS Statistics for Windows, version 24 (IBM Corp., NY, USA).

\section{Results}

\section{Demographic and clinical characteristics}

Page $3 / 13$ 
Of the 347 oncological and 427 cardiovascular hospitals, 130 oncological physicians (37.5\%), 94 oncological nurses (27.1\%), 120 cardiovascular physicians (28.1\%), and 93 cardiovascular nurses (21.8\%) were included in the analysis (Fig. 1). The characteristics of the study participants and hospitals are listed in Table 1 . More than $90 \%$ of physicians were specialized, such as lung cancer or cardiovascular specialists, and almost half of the nurses were certified in a special field, including cancer nursing or palliative care. The sex ratio (men:women) was 1.4:1. In both cancer and cardiovascular hospitals, more than $90 \%$ were general hospitals, almost $60 \%$ were large-scale facilities ( $\geq 500$ hospital beds), more than $80 \%$ had palliative care teams, and almost $70 \%$ had psychiatric or psychological care specialists. 


\begin{tabular}{|c|c|c|}
\hline & $\begin{array}{l}\text { Oncological hospitals } \\
(n=224)\end{array}$ & $\begin{array}{l}\text { Cardiovascular hospitals } \\
(n=213)\end{array}$ \\
\hline \multicolumn{3}{|l|}{ Licenses } \\
\hline Physicians & $130(58.0)$ & $120(56.3)$ \\
\hline -Specialist & $122(54.5)$ & $116(54.5)$ \\
\hline Nurses & $94(42.0)$ & $93(43.7)$ \\
\hline - Certified nurse specialist & $3(1.3)$ & $4(1.9)$ \\
\hline - Certified nurse & $48(21.4)$ & $28(13.1)$ \\
\hline \multicolumn{3}{|l|}{ Sex } \\
\hline Men & $123(55.9)$ & $123(58.6)$ \\
\hline Women & $97(44.1)$ & $87(41.4)$ \\
\hline \multicolumn{3}{|l|}{ Age } \\
\hline 21-30 years old & $5(2.2)$ & $5(2.4)$ \\
\hline $31-40$ years old & $43(19.3)$ & $50(23.7)$ \\
\hline $41-50$ years old & $82(36.8)$ & $86(40.8)$ \\
\hline $51-60$ years old & $81(36.3)$ & $66(31.3)$ \\
\hline$>61$ years old & $12(5.4)$ & $4(1.9)$ \\
\hline \multicolumn{3}{|l|}{ Area } \\
\hline Hokkaido / Tohoku area & $32(15.2)$ & $31(15.3)$ \\
\hline $\begin{array}{l}\text { Kanto / Koshinetsu area } \\
\text { (except for Tokyo) }\end{array}$ & $69(32.9)$ & $56(27.6)$ \\
\hline Tokyo & $17(8.1)$ & $16(7.9)$ \\
\hline Chubu / Hokuriku area & $12(5.7)$ & $12(5.9)$ \\
\hline Kinki area & $27(12.9)$ & $33(16.3)$ \\
\hline Chugoku / Shikoku area & $33(15.7)$ & $24(11.8)$ \\
\hline Kyushu / Okinawa area & $20(9.5)$ & $31(15.3)$ \\
\hline \multicolumn{3}{|l|}{ Hospital type } \\
\hline National medical center & $1(0.5)$ & $3(1.4)$ \\
\hline Academic medical center & $51(23.6)$ & $60(28.7)$ \\
\hline General hospital except academic medical center & $157(72.7)$ & $125(59.8)$ \\
\hline Specialized hospital & $7(3.2)$ & $21(10.0)$ \\
\hline \multicolumn{3}{|l|}{ Number of hospital beds } \\
\hline$<300$ & $8(3.7)$ & $23(10.8)$ \\
\hline$\geq 300,<500$ & $81(37.1)$ & $64(30.1)$ \\
\hline$\geq 500$ & $129(59.2)$ & $126(59.2)$ \\
\hline \multicolumn{3}{|l|}{ Palliative care unit in hospital } \\
\hline Yes & $67(30.2)$ & $59(27.7)$ \\
\hline No & $155(69.8)$ & $150(70.4)$ \\
\hline \multicolumn{3}{|l|}{ Palliative care team in hospital } \\
\hline Yes & $223(100.0)$ & $185(87.3)$ \\
\hline No & $0(0.0)$ & $22(10.4)$ \\
\hline
\end{tabular}




\begin{tabular}{|lll|}
\hline & $\begin{array}{l}\text { Oncological hospitals } \\
(\boldsymbol{n = 2 2 4 )}\end{array}$ & $\begin{array}{l}\text { Cardiovascular hospitals } \\
(\boldsymbol{n = 2 1 3})\end{array}$ \\
\hline Yes & $89(40.5)$ & $88(41.7)$ \\
\hline No & $114(51.8)$ & $106(50.2)$ \\
\hline Palliative care physicians in hospital & & $144(67.6)$ \\
\hline Yes & $166(75.5)$ & $60(28.2)$ \\
\hline No & $53(24.1)$ & $165(77.5)$ \\
\hline Psychiatrists in hospital & & $47(22.1)$ \\
\hline Yes & $177(79.4)$ & $140(65.7)$ \\
\hline No & $44(19.7)$ & $59(27.7)$ \\
\hline Clinical psychologists in hospital & & \\
\hline Yes & $161(73.2)$ & \\
\hline No & $40(18.2)$ & \\
\hline
\end{tabular}

\section{The difficulty of providing end-of-life palliative and psychiatric care}

We found that the Palliative Care Difficulties Scale scores were significantly higher in health care providers among cardiovascular hospitals compared with oncological hospitals for "alleviating symptoms" and "expert support" $(F[423]=8.63, p=0.00$ and $F[414]=18.96, p=0.00$, respectively), whereas no significant differences were found for any other factor $(F[426]=3.50, p=0.06$ for multidisciplinary communication; $F[424]=2.82, p=0.09$ for communication with patient/family; $F[423]=1.11, p=0.29$ for community coordination) (Fig. 2).

The frequency of difficulties in providing end-of-life psychiatric care according to the $\chi^{2}$ test and exact probability test is shown in Fig. 3. A total of 135 (62.2\%) oncological and 125 (59.8\%) cardiovascular health care providers had difficulties in providing end-of-life psychiatric care. There was no significant difference in the frequency of difficulties between oncological and cardiovascular hospitals $\left(\chi^{2}[1]=0.26, p=0.62\right)$.

\section{The barrier of providing end-of-life psychiatric care using qualitative methods}

We extracted 52 attributes from the content analysis, 40 of which were classified by the semantic content into "patients' personal problems," "family members' problems," "professionals' personal problems," "communication problems between professionals and patients," "problems specific to end-of-life care," "problems specific to psychiatric care," "problems of institution or system," and "problems specific to non-cancer patients" (Table 2). The Kappa coefficient derived by the two independent coders was 0.54 in the random $20 \%$ data of this study. 


\begin{tabular}{|c|c|c|c|c|c|c|}
\hline & \multicolumn{2}{|c|}{ Total } & \multicolumn{2}{|c|}{$\begin{array}{l}\text { Oncological } \\
\text { hospitals } \\
(n=117)\end{array}$} & \multicolumn{2}{|c|}{$\begin{array}{l}\text { Cardiovascular } \\
\text { hospitals } \\
(n=106)\end{array}$} \\
\hline & $n$ & (\%) & $n$ & $(\%)$ & $n$ & (\%) \\
\hline \multicolumn{7}{|l|}{ A: Patients' personal problems } \\
\hline 1. Accepting reality and physical condition (A5) & 14 & $(6.3)$ & 8 & $(6.8)$ & 6 & $(5.7)$ \\
\hline 2. Lack of emotion expression (A8) & 12 & $(5.4)$ & 6 & $(5.1)$ & 6 & $(5.7)$ \\
\hline 3. Severe depression or suicide ideation (A7) & 5 & $(2.2)$ & 2 & $(1.7)$ & 3 & $(2.8)$ \\
\hline 4. Problems of cognitive function or comprehension (A4) & 8 & (3.6) & 6 & $(5.1)$ & 2 & $(1.9)$ \\
\hline 5. Depression (A2) & 8 & (3.6) & 4 & $(3.4)$ & 4 & (3.8) \\
\hline 6. Refusal of psychiatric care (A6) & 7 & (3.1) & 4 & $(3.4)$ & 3 & $(2.8)$ \\
\hline 7. Anxiety or embarrassment (A1) & 5 & $(2.2)$ & 5 & $(4.3)$ & 0 & $(0.0)$ \\
\hline 8. Problems specific to young adults (A9) & 4 & $(1.8)$ & 3 & $(2.6)$ & 1 & $(0.9)$ \\
\hline 9. Aggression (A3) & 3 & $(1.3)$ & 2 & $(1.7)$ & 1 & $(0.9)$ \\
\hline \multicolumn{7}{|l|}{ B: Family members' problems } \\
\hline 10. Lack of family support (B2) & 13 & $(5.8)$ & 7 & $(6.0)$ & 6 & $(5.7)$ \\
\hline 11. Accepting reality among family members (B1) & 13 & $(5.8)$ & 8 & $(6.8)$ & 5 & $(4.7)$ \\
\hline 12. Differences in opinions or comprehension among family members (B4) & 10 & $(4.5)$ & 9 & $(7.7)$ & 1 & $(0.9)$ \\
\hline 13. Problems of family relationship (B3) & 3 & (1.3) & 1 & $(0.9)$ & 2 & $(1.9)$ \\
\hline \multicolumn{7}{|l|}{ C: Professionals' personal problems } \\
\hline 14. Problems of time and place (C1) & 33 & $(14.8)$ & 18 & $(15.4)$ & 15 & $(14.2)$ \\
\hline 15. Lack of self-confidence in one's skills in psychiatric care (C2) & 20 & $(9.0)$ & 9 & $(7.7)$ & 11 & $(10.4)$ \\
\hline 16. Problems related to inter-professional team work (C5) & 14 & $(6.3)$ & 8 & $(6.8)$ & 6 & $(5.7)$ \\
\hline 17. Ability differences between health care providers (C4) & 9 & $(4.0)$ & 6 & $(5.1)$ & 3 & $(2.8)$ \\
\hline 18. Psychological burden in health care providers (C3) & 3 & (1.3) & 1 & $(0.9)$ & 2 & $(1.9)$ \\
\hline \multicolumn{7}{|l|}{ D: Communication problems between professionals and patients } \\
\hline 19. Lack of trust between professionals and patients (D2) & 7 & $(3.1)$ & 5 & $(4.3)$ & 2 & $(1.9)$ \\
\hline 20. Differences in opinions or comprehension in professionals vs. patients (D1) & 4 & $(1.8)$ & 3 & $(2.6)$ & 1 & $(0.9)$ \\
\hline \multicolumn{7}{|l|}{ E: Problems specific to end-of-life care } \\
\hline 21. Difficulty of psychological care for patients to whom the "bad news" were not disclosed (E5) & 10 & $(4.5)$ & 5 & $(4.3)$ & 5 & $(4.7)$ \\
\hline 22. Difficulty of psychological care after disclosure about "bad news" (E4) & 10 & $(4.5)$ & 4 & $(3.4)$ & 6 & $(5.7)$ \\
\hline 23. Circumstances cannot meet with the patients' wishes (E7) & 6 & $(2.7)$ & 1 & $(0.9)$ & 5 & $(4.7)$ \\
\hline 24. Problems of acute deterioration (E2) & 5 & $(2.2)$ & 2 & $(1.7)$ & 3 & $(2.8)$ \\
\hline 25. Problems of spiritual pain and acceptance of death (E3) & 4 & $(1.8)$ & 2 & $(1.7)$ & 2 & $(1.9)$ \\
\hline $\begin{array}{l}\text { 26. Difficulty of psychological care for patients to whom the "bad news" were disclosed at a late } \\
\text { time point (E6) }\end{array}$ & 2 & $(0.9)$ & 0 & $(0.0)$ & 2 & $(1.9)$ \\
\hline 27. Problems of physical pain (E1) & 2 & $(0.9)$ & 1 & $(0.9)$ & 1 & $(0.9)$ \\
\hline \multicolumn{7}{|l|}{ F: Problems specific to psychiatric care } \\
\hline 28. Necessity of individual care for each patient (F2) & 14 & $(6.3)$ & 7 & $(6.0)$ & 7 & $(6.6)$ \\
\hline 29. Difficulty of psychiatric assessment and intervention (F1) & 7 & $(3.1)$ & 3 & $(2.6)$ & 4 & (3.8) \\
\hline 30. Lack of robust policy or correct answer (F3) & 2 & $(0.9)$ & 1 & $(0.9)$ & 1 & $(0.9)$ \\
\hline \multicolumn{7}{|l|}{ G: Problems of institution or system } \\
\hline 31. Lack of professional team or health care providers (G1) & 12 & $(5.4)$ & 4 & $(3.4)$ & 8 & $(7.5)$ \\
\hline
\end{tabular}




\begin{tabular}{|c|c|c|c|c|c|c|}
\hline \multirow[b]{2}{*}{ 32. Lack of training system for psychiatric care (G3) } & \multicolumn{2}{|c|}{ Total } & \multicolumn{2}{|c|}{$\begin{array}{l}\text { Oncological } \\
\text { hospitals } \\
(n=117)\end{array}$} & \multicolumn{2}{|c|}{$\begin{array}{l}\text { Cardiovascular } \\
\text { hospitals } \\
(n=106)\end{array}$} \\
\hline & 7 & $(3.1)$ & 1 & $(0.9)$ & 6 & $(5.7)$ \\
\hline 33. Short-handed conditions (G2) & 6 & $(2.7)$ & 5 & $(4.3)$ & 1 & $(0.9)$ \\
\hline 34. Difficulty of compatibility with outpatient service (G4) & 5 & $(2.2)$ & 5 & $(4.3)$ & 0 & $(0.0)$ \\
\hline 35. Difficulty of participating in informed consent (G5) & 4 & $(1.8)$ & 3 & $(2.6)$ & 1 & $(0.9)$ \\
\hline \multicolumn{7}{|l|}{$\mathrm{H}$ : Problems specific to non-cancer patients } \\
\hline 36. Difficulty of evaluating prognostic prediction in non-cancer patients ( $\mathrm{H} 2)$ & 10 & (4.5) & 0 & $(0.0)$ & 10 & $(9.4)$ \\
\hline 37. Lack of practice guidelines for non-cancer patients $(\mathrm{H} 1)$ & 4 & $(1.8)$ & 0 & $(0.0)$ & 4 & (3.8) \\
\hline $\begin{array}{l}\text { 38. Lack of understanding about palliative care for non-cancer patients in patients or family } \\
\text { members }(\mathrm{H} 3)\end{array}$ & 3 & $(1.3)$ & 0 & $(0.0)$ & 3 & (2.8) \\
\hline 39. Lack of experience in palliative care for non-cancer patients in health care providers $(\mathrm{H} 4)$ & 4 & $(1.8)$ & 1 & $(0.9)$ & 3 & (2.8) \\
\hline $\begin{array}{l}\text { 40. Lack of professional team or health care providers who specialize in palliative care for non- } \\
\text { cancer patients (H5) }\end{array}$ & 3 & (1.3) & 0 & $(0.0)$ & 3 & (2.8) \\
\hline
\end{tabular}

The frequency of barriers to providing psychiatric end-of-life care is shown in Table 3. We found that problems specific to non-cancer patients occurred more frequently in health care providers among cardiovascular than oncological hospitals $\left(\chi^{2}[1]=22.475, p=0.00\right)$. There was no significant difference between the frequency of any other barrier between health care providers among oncological and cardiovascular hospitals.

Table 3

Differences in barriers to providing end-of-life psychiatric care between oncological and cardiovascular hospitals

\begin{tabular}{|c|c|c|c|c|c|c|c|c|}
\hline & \multicolumn{2}{|c|}{ Total } & \multicolumn{2}{|c|}{$\begin{array}{l}\text { Oncological } \\
\text { hospitals } \\
(n=117)\end{array}$} & \multicolumn{2}{|c|}{$\begin{array}{l}\text { Cardiovascular } \\
\text { hospitals } \\
(n=106)\end{array}$} & \multirow[b]{2}{*}{$x^{2}$} & \multirow[b]{2}{*}{$p$} \\
\hline & $n$ & $(\%)$ & $n$ & (\%) & $n$ & $(\%)$ & & \\
\hline A: Patients' personal problems & 56 & $(25.1)$ & 33 & $(28.2)$ & 23 & $(21.7)$ & 1.25 & 0.26 \\
\hline B: Family members' problems & 38 & $(17.0)$ & 24 & $(20.5)$ & 14 & $(13.2)$ & 2.10 & 0.15 \\
\hline C: Professionals' personal problems & 65 & $(29.1)$ & 30 & $(25.6)$ & 35 & $(33.0)$ & 1.47 & 0.23 \\
\hline $\begin{array}{l}\text { D: Communication problems between } \\
\text { professionals and patients }\end{array}$ & 11 & $(4.9)$ & 8 & $(6.8)$ & 3 & $(2.8)$ & 1.91 & 0.17 \\
\hline E: Problems specific to end-of-life care & 34 & $(15.2)$ & 13 & $(11.1)$ & 21 & $(19.8)$ & 3.26 & 0.07 \\
\hline F: Problems specific to psychiatric care & 23 & $(10.3)$ & 11 & $(9.4)$ & 12 & $(11.3)$ & .22 & 0.64 \\
\hline G: Problems of institution or system & 32 & $(14.3)$ & 17 & $(14.5)$ & 15 & $(14.2)$ & .01 & 0.94 \\
\hline H: Problems specific to non-cancer patients & 22 & $(9.9)$ & 1 & $(0.9)$ & 21 & $(19.8)$ & 22.48 & $0.00^{*}$ \\
\hline${ }^{*} p<0.05$ & & & & & & & & \\
\hline
\end{tabular}

\section{Discussion}

This is the first study that investigated the barriers to providing end-of-life psychiatric care. Our results yielded two major findings. First, the health care providers included in this study were found to have eight barriers to providing psychiatric care: problems concerning the (1) patients, (2) family members, and (3) professionals, (4) difficulties in the communication amongst professionals, difficulties specific to (5) end-of-life care, (6) psychiatric care, or (7) non-cancer patients, and (8) issues related to the institution or system. Second, cardiovascular health care providers have psychiatric care problems specific to non-cancer patients, such as obtaining professional support, useful guidelines, or training opportunities. This study was useful in exploring solutions for providing sufficient psychiatric care for end-stage HF patients due to the extraction of barriers using a bottom-up qualitative approach.

Our results indicate that there are three challenges in providing psychiatric care to end-of-life patients. First, cardiovascular health care providers find it particularly difficult to improve their knowledge and skills in psychiatric assessment and treatment of psychological as well as cardiac symptoms. In particular, depression, in addition to fatigue or pain, is one of the most common symptoms and imposes a heavy burden on patients with advanced HF [12, 13, 37]. Some clinical practice guidelines on HF emphasize the need for psychiatric care for depressive HF patients as part of symptom management in Western countries $[5,38]$. However, even these guidelines have insufficient information about a specific psychiatric assessment and treatment for patients with HF. 
Participants in this study also described that they had little access to improve their knowledge and skills in psychiatric care. In cancer patients, lack of knowledge and training is a barrier to providing psychiatric care [39], and therefore some Japanese academic societies have held seminars or workshops to promote psychiatric care knowledge for oncologists or any other health care providers in the last few decades. Taken together, we recommend an expansion of the training system and provision of detailed guidelines as a way to provide access to methods of psychiatric assessment and treatment for patients with advanced $\mathrm{HF}$.

In addition, physical symptom management was also identified as a difficult problem for cardiovascular professionals compared with oncological colleagues in this study. Interventions directed at alleviating physical symptoms related to HF can lead to a reduction in psychological symptoms in palliative care [40]. In the future, we should develop a training system for end-of-life care professionals in parallel with both physical and psychiatric care.

Second, many health care providers felt that it was difficult to coordinate professional-patient relationships in both cardiovascular and oncological settings. Interventions to enhance communication between professionals and patients can improve the psychological well-being [41]. The professional-patient relationship and communication are also important for the quality and outcome of medical treatment [42, 43]. Particularly in palliative settings, a lack of communication between professionals and patients can lead to the inhibition of critical decisions such as ICD deactivations [44, 45]. Practically, general education and specialized education can improve communication skills among health care providers and facilitate professional-patient communication [46, 47]. Advanced care planning can also encourage effective communication between professionals and patients with HF [48, 49]. Therefore, we conclude that a useful tool or training system for improving communication skills as well as psychiatric care skills among health care providers could enhance end-of-life care in cardiovascular settings.

Third, professionals' personal psychological or physical distress can be a barrier to providing psychiatric care. Professional participants in this study described that many cardiovascular and oncological hospitals do not have sufficient staff and are consequently overwhelmed by the workload, leading to unsatisfactory psychiatric care for palliative patients. Health care providers also feel unable to provide sufficient spiritual psychiatric care for end-of-life patients [29]. Reducing the workload and ensuring adequate time management for health care providers remain critical goals in modern Japanese medical settings.

\section{Limitations}

Our study has two major limitations. First, recall bias may have occurred because of the self-reported nature of the questionnaires. However, we conducted a content analysis by two researchers independently and ensured objectivity. Second, selection bias might have occurred because of the implementation of a national study exclusively in Japan. Therefore, future studies investigating the same issues in other countries will be of importance to confirm our findings.

\section{Conclusions}

Our study suggests that health care providers in cardiovascular hospitals, in contrast to oncological counterparts, experience problems in obtaining useful guidelines or training opportunities. We should provide continuous educational opportunities for health care providers involved with psychiatric and palliative care for patients with HF. However, our study also indicates that both oncological and cardiovascular health care providers experience difficulties in providing end-of-life psychiatric care, which stem from patients' or health care providers' personal problems, among others. Therefore, we should also develop strategies to overcome not only the understaffing situation in medical services but also a lack of professionals' psychiatric care skills.

\section{Declarations}

\section{Ethics approval and consent to participate}

Written informed consent to participate was obtained from all the participants. We informed the aim of the present study and their right to quit the survey before they participated. Then, they marked a form checkbox field as a statement of consent when they returned the questionnaires. Our study was approved without undergoing assessment by the institutional review board at the Tokyo Medical and Dental University in Japan, as it was an anonymized non-invasive self-completed questionnaire study for health care providers. However, all procedures were in accordance with the ethical standards of the responsible committees on human experimentation (institutional and national) and with the Helsinki Declaration of 1975, as revised in 2000.

\section{Consent for publication}

Not applicable

\section{Availability of data and materials}

The datasets generated and/or analyzed during the current study are not publicly available due not to state clearly in informed consent form but are available from the corresponding author on reasonable request.

\section{Competing Interests}


IK is an advisor for personal health care services by Clinical Study Support, Inc. FY received research grants from the Murata Science Foundation. TH is an advisor of a clinical trial by Taisho Pharmaceutical Holdings and a committee member of the Medical Research Ethics Committee of the Nikon Corporation and the Japan Aerospace Exploration Agency. MS, CH, IH, MH, TT, and ME have no competing interests to report.

\section{Funding}

This study was supported by a grant from JSPS KAKENHI (Grant Number: JP16J00179) and scholarship donations from Astellas Pharma Inc., Mitsubishi Tanabe Pharma Corporation, MSD K.K., Otsuka Pharmaceutical, Pfizer Inc., and Takeda Pharmaceutical Company Ltd. However, the funders had no role in the study design, data collection and analysis, decision to publish, or preparation of the manuscript.

\section{Authors' contributions}

IK, MS, and ME conceptualized this study. IK curated the data. IK, MS, and IH conducted the formal analyses. IK and ME acquired the funding. IK conducted the study, designed the study methodology, oversaw the project administration, obtained the study's resources, and operated the software. $\mathrm{CH}$ supervised the qualitative analyses. TH and TT supervised the study. IK validated the study results, created the visualizations, and wrote the original draft. MS, $\mathrm{CH}$, IH, $\mathrm{FY}$, $\mathrm{MH}$, $\mathrm{TH}, \mathrm{TT}$, and ME reviewed and edited the draft. All authors read and approved the final manuscript.

\section{Acknowledgements}

We are grateful to Satoko Ogi, Tomoko Sugano, Wakana Takeshita, and Yoriko Mizukane for assisting in making a list of delivery addresses and affixing a shipping label to mailing envelopes. We would also like to thank all health care providers who participated in this study.

\section{References}

1. The World Health Organization (WHO) (2018) The top 10 causes of death. https://www.who.int/news-room/fact-sheets/detail/the-top-10-causes-of-death

2. Dagenais GR, Leong DP, Rangarajan S, Lanas F, Lopez-Jaramillo P, Gupta R, Diaz R, Avezum A, Oliveira GBF, Wielgosz A, Parambath SR, Mony P, Alhabib KF, Temizhan A, Ismail N, Chifamba J, Yeates K, Khatib R, Rahman O, Zatonska K, Kazmi K, Wei L, Zhu J, Rosengren A, Vijayakumar K, Kaur M, Mohan V, Yusufali A, Kelishadi R, Teo KK, Joseph P, Yusuf S (2020) Variations in common diseases, hospital admissions, and deaths in middle-aged adults in 21 countries from five continents (PURE): A prospective cohort study. Lancet 395:785-794.https://doi.org/10.1016/S0140-6736(19)32007-0

3. Shah KS, Xu H, Matsouaka RA, Bhatt DL, Heidenreich PA, Hernandez AF, Devore AD, Yancy CW, Fonarow GC (2017) Heart failure with preserved, borderline, and reduced ejection fraction: 5-Year Outcomes. J Am Coll Cardiol 70:2476-2486.https://doi.org/10.1016/j.jacc.2017.08.074

4. Cook C, Cole G, Asaria P, Jabbour R, Francis DP (2014) The annual global economic burden of heart failure. Int J Cardiol 171:368376.https://doi.org/10.1016/j.ijcard.2013.12.028

5. Sobanski PZ, Alt-Epping B, Currow DC, Goodlin SJ, Grodzicki T, Hogg K, Janssen DJA, Johnson MJ, Krajnik M, Leget C, Martínez-Sellés M, Moroni M, Mueller PS, Ryder M, Simon ST, Stowe E, Larkin PJ (2020) Palliative care for people living with heart failure: European Association for Palliative Care Task Force expert position statement. Cardiovasc Res 116:12-27.https://doi.org/10.1093/cvr/cvz200

6. Celano CM, Villegas AC, Albanese AM, Gaggin HK, Huffman JC (2018) Depression and anxiety in heart failure: A Review. Harv Rev Psychiatry 26:175184.https://doi.org/10.1097/HRP.0000000000000162

7. Kuhlmann SL, Arolt V, Haverkamp W, Martus P, Ströhle A, Waltenberger J, Rieckmann N, Müller-Nordhorn J (2019) Prevalence, 12-month prognosis, and clinical management need of depression in coronary heart disease patients: A prospective cohort study. Psychother Psychosom 88:300311.https://doi.org/10.1159/000501502

8. Rasputina L, Rasputin V, Ovcharuk M, Serhiichuk O, Broniuk A (2016) Prevalence of depression and its grading in patients with coronary heart disease. Georgian Med News (259):48-53

9. Rutledge T, Reis VA, Linke SE, Greenberg BH, Mills PJ (2006) Depression in heart failure a meta-analytic review of prevalence, intervention effects, and associations with clinical outcomes. J Am Coll Cardiol 48:1527-1537.https://doi.org/10.1016/j.jacc.2006.06.055

10. Easton K, Coventry P, Lovell K, Carter LA, Deaton C (2016) Prevalence and measurement of anxiety in samples of patients with heart failure: Metaanalysis. J Cardiovasc Nurs 31:367-379.https://doi.org/10.1097/JCN.0000000000000265

11. Jani BD, Mair FS, Roger VL, Weston SA, Jiang R, Chamberlain AM (2016) Comorbid depression and heart failure: A community cohort study. PLOS ONE 11:e0158570. doi:10.1371/journal.pone.0158570

12. Diamant MJ, Keshmiri H, Toma M (2020) End-of-life care in patients with advanced heart failure. Curr Opin Cardiol 35:156161.https://doi.org/10.1097/HCO.0000000000000712

13. Lowey SE (2018) Palliative care in the management of patients with advanced heart failure. Adv Exp Med Biol 1067:295311.https://doi.org/10.1007/5584_2017_115

14. Rajeswaran T, Plymen CM, Doherty AM (2018) The effect of antidepressant medications in the management of heart failure on outcomes: Mortality, cardiovascular function and depression - A systematic review. Int J Psychiatry Clin Pract 22:164-169.https://doi.org/10.1080/13651501.2017.1401085

15. Celano CM, Villegas AC, Albanese AM, Gaggin HK, Huffman JC (2018) Depression and anxiety in heart failure: A review. Harv Rev Psychiatry 26:175184.https://doi.org/10.1097/HRP.0000000000000162 
16. WH, YZ, J M, et al (2020) Effect of antidepressants on death in patients with heart failure: a systematic review and meta-analysis. Heart fail rev 25:919926. https://doi.org/10.1007/S10741-019-09850-W

17. Jeyanantham K, Kotecha D, Thanki D, Dekker R, Lane DA (2017) Effects of cognitive behavioural therapy for depression in heart failure patients: A systematic review and meta-analysis. Heart Fail Rev 22:731-741.https://doi.org/10.1007/s10741-017-9640-5

18. Peng Y, Fang J, Huang W, Qin S (2019) Efficacy of cognitive behavioral therapy for heart failure. Int Heart J 60:665-670.https://doi.org/10.1536/ihj.18408

19. Kwekkeboom KL, Bratzke LC (2016) A Systematic Review of Relaxation, Meditation, and Guided Imagery Strategies for Symptom Management in Heart Failure. J Cardiovasc Nurs 31:457-468.https://doi.org/10.1097/JCN.0000000000000274

20. MJ S, LW, J T, et al (2009) The Support, Education, and Research in Chronic Heart Failure Study (Search): a mindfulness-based psychoeducational intervention improves depression and clinical symptoms in patients with chronic heart failure. Am heart J 157:84-90. https://doi.org/10.1016/J.AHJ.2008.08.033

21. Murray SA, Kendall M, Grant E, Boyd K, Barclay S, Sheikh A (2007) Patterns of social, psychological, and spiritual decline toward the end of life in lung cancer and heart failure. J Pain Symptom Manage 34:393-402.https://doi.org/10.1016/J.JPAINSYMMAN.2006.12.009

22. MacMahon KM, Lip GY (2002) Psychological factors in heart failure: A review of the literature. Arch Intern Med 162:509516.https://doi.org/10.1001/ARCHINTE.162.5.509

23. Wang CW, Chow AY, Chan CL (2017) The effects of life review interventions on spiritual well-being, psychological distress, and quality of life in patients with terminal or advanced cancer: A systematic review and meta-analysis of randomized controlled trials. Palliat Med 31:883894.https://doi.org/10.1177/0269216317705101

24. Okuyama T, Akechi T, Mackenzie L, Furukawa TA (2017) Psychotherapy for depression among advanced, incurable cancer patients: A systematic review and meta-analysis. Cancer Treat Rev 56:16-27.https://doi.org/10.1016/j.ctrv.2017.03.012

25. ST S, AP, L R, et al (2020) The Palliative Care of Patients With Incurable Cancer. Dtsch. Arztebl int 116:108-115. https://doi.org/10.3238/ARZTEBL.2020.0108

26. Inoue A, Yamaguchi T, Tanaka K, Sakashita A, Aoe K, Seki N, Hagiwara K (2019) Benefits of a nationwide palliative care education program on lung cancer physicians. Intern Med 58:1399-1403.https://doi.org/10.2169/INTERNALMEDICINE.0872-18

27. Howell D, Keshavarz H, Esplen MJ, et al (2015) Pan-Canadian practice guideline: Screening, assessment and management of psychosocial distress, depression and anxiety in adults with cancer. In: Can. Assoc. Psychosoc Oncol. http://www.capo.ca/. Accessed 23 Aug 2021

28. Chen J, Walsh S, Delaney C, Cong X (2020) Pain management in patients with heart failure: A survey of nurses' perception. Pain Manag Nurs 21:365370.https://doi.org/10.1016/j.pmn.2019.09.004

29. Harasym P, Brisbin S, Afzaal M, Sinnarajah A, Venturato L, Quail P, Kaasalainen S, Straus SE, Sussman T, Virk N, Holroyd-Leduc J (2020) Barriers and facilitators to optimal supportive end-of-life palliative care in long-term care facilities: A qualitative descriptive study of community-based and specialist palliative care physicians' experiences, perceptions and perspectives. BMJ Open 10:e037466. doi:10.1136/bmjopen-2020-037466

30. Brasi ELD, Giannetta N, Ercolani S, et al (2020) Nurses' moral distress in end-of-life care: A qualitative study. Nurs Ethics. doi:10.1177/0969733020964859

31. Nakazawa Y, Miyashita M, Morita T, Umeda M, Oyagi Y, Ogasawara T (2010) The palliative care self-reported practices scale and the palliative care difficulties scale: Reliability and validity of two scales evaluating self-reported practices and difficulties experienced in palliative care by health professionals. J Palliat Med 13:427-437.https://doi.org/10.1089/jpm.2009.0289

32. Krippendorff KH (2018) Content analysis: An introduction to its methodology. SAGE Publications, Inc

33. MM, KH, T M, et al (2008) Barriers to referral to inpatient palliative care units in Japan: a qualitative survey with content analysis. Support care cancer 16:217-222. https://doi.org/10.1007/S00520-007-0215-1

34. Hirai K, Miyashita M, Morita T, Sanjo M, Uchitomi Y (2006) Good death in Japanese cancer care: A qualitative study. J Pain Symptom Manage 31:140147.https://doi.org/10.1016/j.jpainsymman.2005.06.012

35. Lombard M, Snyder-Duch J, Bracken CC (2005) Practical resources for assessing and reporting intercoder reliability in content analysis research projects. https://www.researchgate.net/publication/242785900_Practical_Resources_for_Assessing_and_Reporting_Intercoder_Reliability_in_Content_Analysis_Res

36. Lombard M, Snyder-Duch J, Bracken CC (2004) A call for standardization in content analysis reliability. Hum Comm Res 30:434-437

37. Alpert CM, Smith MA, Hummel SL, Hummel EK (2017) Symptom burden in heart failure: Assessment, impact on outcomes, and management. Heart Fail Rev 22:25-39.https://doi.org/10.1007/S10741-016-9581-4

38. Lichtman JH, Froelicher ES, Blumenthal JA, Carney RM, Doering LV, Frasure-Smith N, Freedland KE, Jaffe AS, Leifheit-Limson EC, Sheps DS, Vaccarino V, Wulsin L, American Heart Association Statistics Committee of the Council on Epidemiology and Prevention and the Council on Cardiovascular and Stroke Nursing (2014)Depression as a risk factor for poor prognosis among patients with acute coronary syndrome: Systematic review and recommendations: A scientific statement from the American Heart Association. Circulation 129:1350-1369.https://doi.org/10.1161/CIR.0000000000000019

39. Granek L, Nakash O, Ariad S, Shapira S, Ben-David M, et al (2019) Strategies and barriers in addressing mental health and suicidality in patients with cancer. Oncol Nurs Forum 46:561-571. DOI:10.1188/19.0NF.561-571

40. Doorenbos AZ, Levy WC, Curtis JR, Dougherty CM (2016) An intervention to enhance goals-of-care communication between heart failure patients and heart failure providers. J Pain Symptom Manage 52:353-360.https://doi.org/10.1016/j.jpainsymman.2016.03.018

41. Prip A, Møller KA, Nielsen DL, Jarden M, Olsen MH, Danielsen AK (2018) The patient-healthcare professional relationship and communication in the oncology outpatient setting: A systematic review. Cancer Nurs 41:E11-E22.https://doi.org/10.1097/NCC.0000000000000533 
42. Farmer SA, Magasi S, Block P, Whelen MJ, Hansen LO, Bonow RO, Schmidt P, Shah A, Grady KL (2016) Patient, caregiver, and physician work in heart failure disease management: A qualitative study of issues that undermine wellness. Mayo Clin Proc 91:1056-

1065.https://doi.org/10.1016/J.MAYOCP.2016.05.016

43. Parajuli J, Tark A, Jao YL, Hupcey J (2020) Barriers to palliative and hospice care utilization in older adults with cancer: A systematic review. J Geriatr Oncol 11:8-16.https://doi.org/10.1016/j.jgo.2019.09.017

44. GoldsteinNe ,MatherH, McKendrick K, Gelfman LP, Hutchinson MD, Lampert R, Lipman HI, Matlock DD, Strand JJ, Swetz KM, Kalman J, Kutner JS, Pinney S, Morrison RS, et al (2019) Improving communication in heart failure Patient Care. J Am Coll Cardiol 74:16821692.https://doi.org/10.1016/J.JACC.2019.07.058

45. Tu J, Kang G, Zhong J, Cheng Y (2019) Outpatient communication patterns in a cancer hospital in China: A qualitative study of doctor-patient encounters. Health Expect 22:594-603.https://doi.org/10.1111/HEX.12890

46. Gelfman LP, Kavalieratos D, Teuteberg WG, Lala A, Goldstein NE (2017) Primary palliative care for heart failure: What is it? How do we implement it? Heart Fail Rev 22:611-620.https://doi.org/10.1007/s10741-017-9604-9

47. Schichtel M, Wee B, Perera R, Onakpoya I (2020) The Effect of Advance Care Planning on Heart Failure: A Systematic Review and Meta-analysis. J Gen Intern Med 35:874-884.https://doi.org/10.1007/S11606-019-05482-W

48. Hauser J (2017) Communication in heart failure and palliative care. Heart Fail Rev 22:535-542.https://doi.org/10.1007/s10741-017-9643-2

49. JG R, CB P, RJ M, et al (2017) Palliative Care in Heart Failure: the PAL-HF Randomized, Controlled Clin Trials J Am Coll Cardiol 70:331-341. https://doi.org/10.1016/J.JACC.2017.05.030

\section{Figures}

Fig. 1
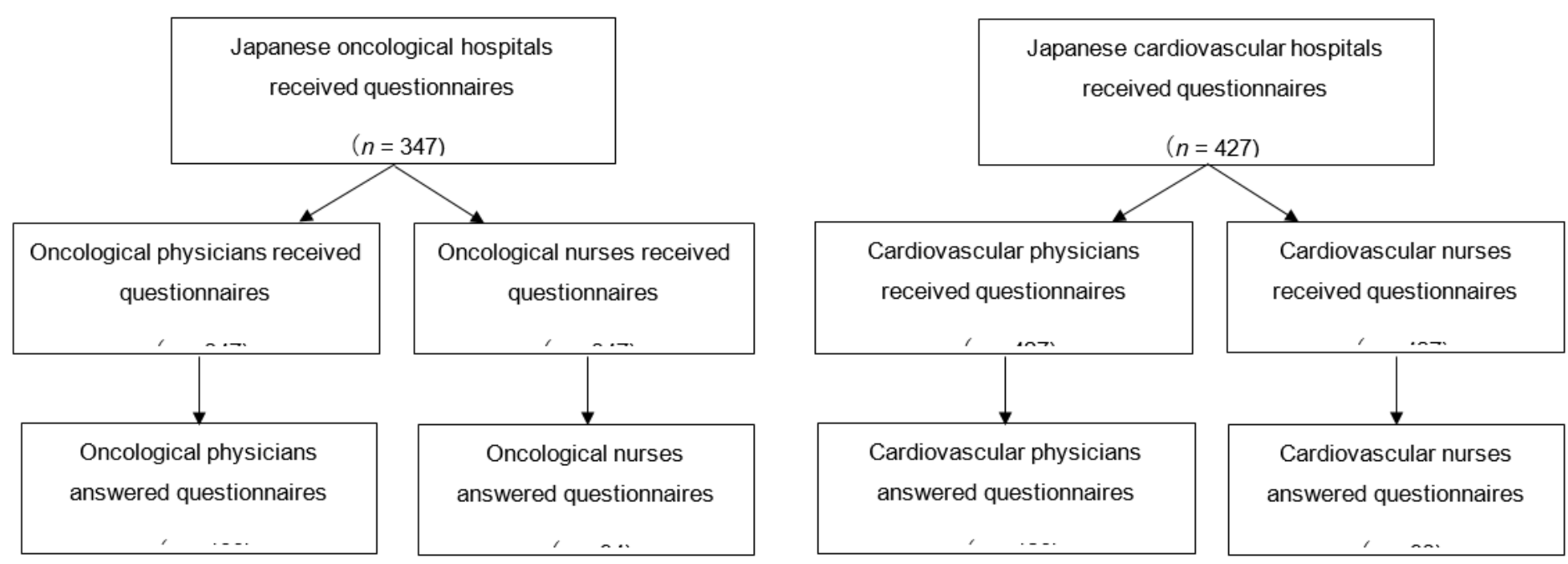

Figure 1

Flow diagram of participants 
Fig. 2

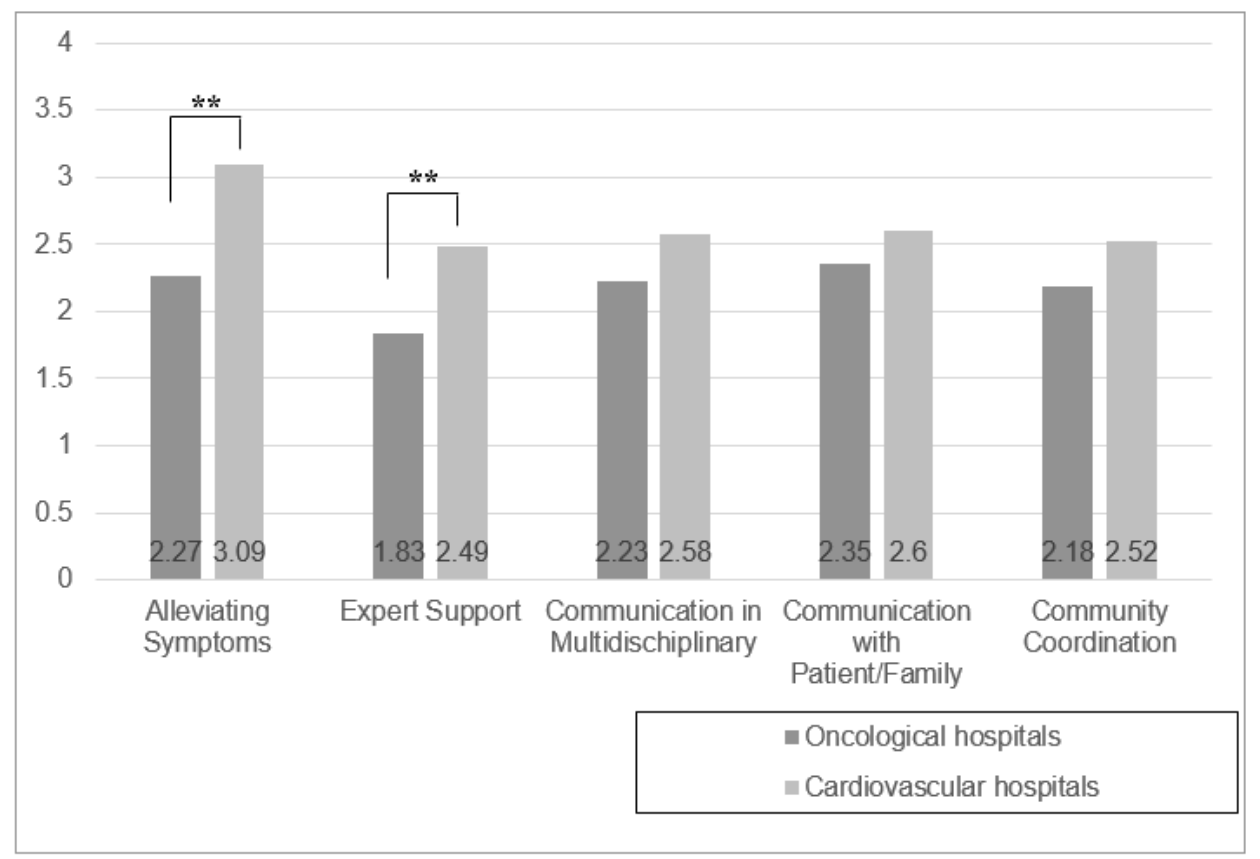

Figure 2

Difficulty of providing palliative care (scores)

Fig. 3

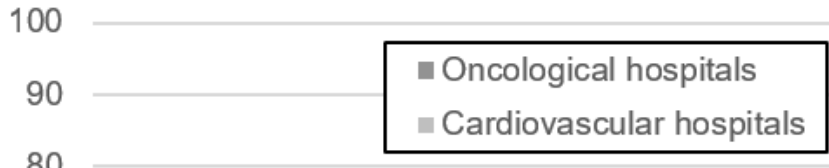

80

70

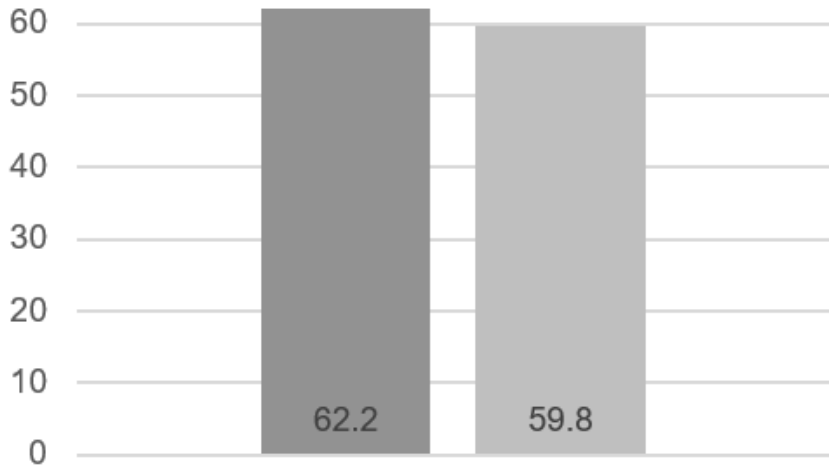

Difficulty of providing psychiatric care in end-of-life

\section{Figure 3}

Difficulty of providing end-of-life psychiatric care (\%) 